\title{
Uniformity and comparability: an analysis of the relevance for the Brazilian capital market ${ }^{*}$
}

\author{
Emanuelle Frasson Guimarães ${ }^{1}$ \\ (D) https://orcid.org/0000-0002-3617-9968 \\ Email: emanuellefgf@gmail.com \\ Suliani Rover ${ }^{1}$ \\ (D) https://orcid.org/0000-0001-8612-2938 \\ Email: suliani.rover@ufsc.br
}

${ }^{1}$ Universidade Federal de Santa Catarina, Programa de Pós-Graduação em Contabilidade, Florianópolis, SC, Brazil

Received on 08.14.2020 - Desk acceptance on 09.21.2020 - $3^{\text {rd }}$ version approved on 09.15.2021 - Ahead of print on 01.21.2022

Editor-in-Chief: Fábio Frezatti

Associate Editor: Eliseu Martins

\begin{abstract}
This research aimed to analyze the relationship between the characteristics of uniformity and comparability and the fundamental qualitative characteristic of relevance of financial reports for the Brazilian capital market, discussing the possibility of a tradeoff between comparability and relevance, the importance of considering both comparability and relevance to maximize the utility of financial statements, and the gaps regarding the "effectiveness" of uniformity and achieving comparability to the detriment of relevance. It is important to investigate the "effectiveness" of uniformity in terms of the utility of the decision due to the confusion that exists between the concepts of uniformity and comparability. The results will encourage regulatory bodies to reflect on the confusion that exists between uniformity and comparability and on fulfilling the characteristics of relevance and comparability, indicating what the relationship is between these from the viewpoint of the capital market. Uniformity is identified by means of the earnings covariance measure and comparability via the accounting function similarity measure. The relevance models are assessed using panel data regressions covering the period from 2013 to 2018 . The sample includes companies from the B3 S.A. - Brasil, Bolsa, Balcão belonging to sectors classified in the Level 2 North American Classification System (NAICS) that comprise at least two companies. The results indicated that uniformity is not relevant for the Brazilian capital market, even when it contributes to comparability. These can be explained by the possible production of superficial comparability. They also revealed that comparability is relevant and positively related to the share price. However, the inclusion of this variable led to a decrease in explanatory power, which may indicate the achievement of comparability to the detriment of relevance. Finally, it is revealed that the Brazilian capital market distinguishes between the concepts of uniformity and comparability when evaluating companies.
\end{abstract}

Keywords: uniformity, comparability, relevance.

Correspondence address

Emanuelle Frasson Guimarães

Universidade Federal de Santa Catarina, Programa de Pós-Graduação em Contabilidade

R. Eng. Agronômico Andrei Cristian Ferreira, s/n - CEP 88040-900

Trindade - Florianópolis - SC - Brazil

*The authors are grateful to the Coordination for the Improvement of Higher Education Personnel (Capes) for its financial support in carrying out this research. 


\section{INTRODUCTION}

The essence of the economic decision is the choice between possible courses of action, which requires an awareness of alternatives and opportunities. Thus, financial information should simplify the comparisons needed for decision making related to the provision of resources to an entity. Users' decisions involve choices between alternatives and, if similar things are not reported in a similar way and different things are not reported differently, financial information users will encounter difficulties in comparing the alternatives and in identifying opportunities for decision making (American Institute of Certified Public Accountants [AICPA], 1973).

From this angle, the relevance of comparability in the users' decision-making model is assumed because the main purpose of financial information in the decisionmaking process is to form a basis for comparability between capital allocation alternatives (Ribeiro et al., 2016b). By means of financial information, users can make comparisons and assessments of the results of transactions and events among companies (AICPA, 1973). With regard to the investment decision-making process, investors assess companies' prospects of growth, risk, and return, and through comparing opportunities they allocate capital (Chartered Financial Analyst [CFA], 2007).

Since the essence of the economic decision is the choice between possible courses of action and the main purpose of financial information in the decision-making model is to form a basis for comparing between capital allocation alternatives (AICPA, 1973; Ribeiro et al., 2016b), comparability is recognized as a qualitative characteristic of improvement for the utility of the decision of the financial information by the Conceptual Framework for Financial Reporting (International Accounting Standards Board - IASB, 2018a). The utility of comparability for the users' decision-making process may be hindered by the confusion that exists between the concepts of comparability and uniformity. This confusion is recognized in the research of Cole et al. (2012), in which $67 \%$ of the individuals interviewed, from among 426, interpreted comparability as uniformity derived from the application of similar accounting methods.

Uniformity is partially compatible with comparability due to the fact it contributes to that qualitative characteristic of improvement only in some situations (Simmons, 1967). The comparability resulting from the application of similar accounting treatments for different economic arrangements or events, that is, resulting from uniformity, is identified as superficial and reproduces one of the dysfunctional aspects due to the possible reduction in the utility of the financial information (Gordon \& Gallery, 2012; Schipper, 2003; Zeff, 2007). Genuine or deep comparability, unlike the superficial sort, depends on the economic event and on the mapping of this in relation to the form of translation to the accounting. In light of this, uniformity does not represent one of the goals for financial reports and may only be relevant in contributing to the achievement of comparability (Hendriksen, 1967).

Despite the possible benefits of comparability, this is not individually responsible for maximizing the utility of financial statements or for making information useful if the latter does not fulfill the fundamental qualitative characteristics of relevance and faithful representation. The Basis for Conclusions, a section that accompanies the Conceptual Structure, highlights that comparable information may not be useful for decision making if it is not relevant or does not faithfully represent what it proposes to represent (IASB, 2018a, 2018b; Simmons, 1967). Schipper (2003) discusses the possibility of a tradeoff between comparability and predictive capacity, one of the aspects of relevance that expresses the ability to make a difference in users' decision making. Sacrificing comparability by prioritizing predictive capacity (relevance) is not inconsistent with the Conceptual Structure (Schipper, 2003). In turn, the application of accounting treatments for prioritizing comparability that are not ideal from a relevance viewpoint is inconsistent as it disregards the secondary role of comparability in relation to relevance (IASB, 2018a; Schipper \& Vincent, 2003).

With regard to the research that has analyzed the relationship between relevance and comparability, the results of Kim et al. (2018) indicated a positive relationship between these characteristics given the greater reaction to earnings news and significant increase in the short window earnings response coefficient (ERC) for a high level of comparability. Choi et al. (2019) identified a positive interaction between comparability and the future ERC (FERC), revealing that comparability results in better informativeness of the share price regarding future earnings.

Due to the confusion between the concepts of uniformity and comparability for financial information users (Cole et al., 2012), questions are raised about the "effectiveness" of uniformity regarding the utility of the decision through its relationship with the fundamental 
qualitative characteristic of relevance (Caylor et al., 2018). According to May (1938), uniformity, despite not representing a goal in itself for financial reports, consists of a help for evaluating accounting records given the absence of trust in the description and judgements made in the interpretation of relevant factors.

Given the possible existence of a trade-off between comparability and relevance (Schipper, 2003), the importance of considering both comparability and relevance in studies to maximize the utility of statements (Simmons, 1967), and the gaps in terms of verifying the "effectiveness" of uniformity by means of its relationship with relevance (Caylor et al., 2018) and in terms of analyzing the achievement of comparability to the detriment of relevance (Schipper \& Vincent, 2003), the following research problem is presented: what is the relationship between the uniformity, comparability, and relevance of financial reports for the Brazilian capital market? The research objective is to analyze the relationship between the characteristics of uniformity and comparability and the fundamental qualitative characteristic of relevance of financial reports for the Brazilian capital market.

Most of the research on comparability does not aim to identify its relevance for the decision-making process and to verify the achievement of comparability to the detriment of relevance (Schipper \& Vincent, 2003; Simmons, 1967). Thus, the intention here is to contribute to the line of studies that investigates relevance, uniformity, and comparability and identifies the "effectiveness" of uniformity in relation to the utility of the decision (Caylor et al., 2018) and the achievement of comparability to the detriment of relevance (Schipper \& Vincent, 2003). The findings of this study indicated that uniformity is not relevant for the Brazilian capital market given the possible production of superficial comparability. Moreover, they revealed that comparability is relevant, but its inclusion resulted in a reduction in explanatory power, which may indicate the achievement of this characteristic to the detriment of relevance.

With regard to the practical perspective, it is believed that the results will encourage regulatory bodies to reflect on the confusion that exists between the concepts of uniformity and comparability, via an analysis of the behaviors of the variables and an indication of the relationship between uniformity and relevance and regarding the fulfillment of the characteristics of relevance and comparability, indicating what the relationship is between the qualitative characteristic of improvement and the fundamental qualitative characteristic from the viewpoint of the capital market. We hope to reveal whether the Brazilian capital market considers the uniformity and comparability of financial reports to be relevant for decision making and whether the respective market distinguishes uniformity from comparability for the process of evaluating the market value of companies.

\section{THEORETICAL FRAMEWORK}

\subsection{Uniformity and Comparability}

Comparability represents a qualitative characteristic of improvement of financial information that provides greater utility to relevant and faithful information through comparing information between different entities and within the same entity in different periods. This characteristic enables the identification and understanding of similarities and differences between items and, for that reason, it requires at least two items (IASB, 2018a).

Using a comparability framework, Gordon and Gallery (2012) distinguished comparability into deep, surface, non-convergent, and intrinsic differences. While deep comparability is recorded when similar economic events are recognized under the same accounting method, the surface sort is recorded when the same accounting method is applied for different economic events (Gordon \& Gallery, 2012). This variety of comparability was already presented by Schipper (2003) and Zeff (2007) as genuine and superficial, respectively. Comparability is also distinguished into non-convergent, when alternative accounting methods are employed for similar underlying economic events, and intrinsic differences, when alternative accounting methods are employed for different underlying economic events (Gordon \& Gallery, 2012).

Since the primary interpretation of comparability, applied in the Trueblood Committee, is that similar situations should appear similar and different situations should appear different ("like things look alike, and unlike things look different"), surface and non-convergent comparability are considered dysfunctional aspects due to a possible reduction in the utility of comparisons of financial information, primarily because they do not 
fulfill the essence of the interpretation of comparability (Trueblood, 1966, p. 189). Deep and intrinsic differences comparability help in achieving the aim of utility of financial information for the decision-making process (Gordon \& Gallery, 2012).

Superficial comparability, recorded through the application of similar accounting treatments for different economic arrangements or events, is a consequence of the uniformization of accounting procedures and may result from the confusion that exists between the concepts of uniformity and comparability. This confusion is recognized in the research of Cole et al. (2012), in which $67 \%$ of the 426 individuals interviewed interpreted comparability as uniformity derived from the application of similar accounting methods, and $31 \%$ considered that "comparability is achieved when all companies can apply an accounting method adapted to their unique circumstances" (Cole et al., 2012, p. 125). In light of this, the conception and differentiation of these concepts are essential, since, despite being convergent to a certain degree, comparability is not uniformity.

Simmons (1967) presents comparability as the equivalent reflection of individual economic circumstances which aims to report similarities as similarities and differences as differences. Uniformity, in turn, corresponds to the absence of any variation in the preparation and presentation of financial statements in terms of reflecting the economic circumstances between two or more companies (Simmons, 1967).

For Simmons (1967), comparability can be seen as a goal of financial reports, and uniformity is partially compatible with this goal as it produces comparability in some situations, though not in all. Similarly, Hendriksen (1967) argues that uniformity is not a goal in itself for financial reports, but rather a means of obtaining comparability between company statements; that is, uniformity may only be relevant in contributing to comparability, given that "the goal is comparability, not uniformity" (Hendriksen, 1967, p. 106).

According to May (1938), despite uniformity not being an objective, it is a way of helping to make the accounting more valuable, especially for unqualified readers. Moreover, May (1938) explains that uniformity is important due to the absence of trust in reports as an interpretation of all the relevant factors according to the best judgement of honest and competent people.

Barth (2013) explains that while comparability results in similarities and differences, uniformity only results in similarities. In light of this, uniformity can hinder comparability by making things similar that, in terms of economic circumstances, are different. To exemplify, Barth (2013) considers the existence of an accounting rule for buildings that requires linear depreciation, a useful life of 30 years, and a residual value of $10 \%$. If that rule were followed, it would mean that all buildings were similar, even if they have a different depreciation pattern, useful life, and residual value. As a result, there would be uniformity without comparability, given that the differences would not be reported as differences, but rather as similarities.

Uniformity, besides possibility leading to less comparability by reporting differences in economic circumstances as similarities, undervalues the signaling of the accounting choices made by managers and hinders the progress of financial reports (Cole et al., 2012). It therefore follows that, despite the terms uniformity and comparability being convergent to a certain degree, uniformity does not necessarily result in comparability, but rather it is characterized as a means of achieving it.

\subsection{Relevance}

The Conceptual Structure assumes the approach of the utility of the decision in the objective of financial reports as a general proposal regarding the provision of financial information that is useful for existing and potential investors, lenders, and other creditors in decision making related to the provision of resources to an entity (IASB, 2018a; Scott, 2015).

According to Scott (2015, p. 82), under decision theory, information is "evidence that has the potential to affect an individual's decision." This view is consistent with the fundamental qualitative characteristic of relevance in which information is considered relevant if it is able to make a difference in users' decision making (IASB, 2018a). The investigation of the relevance of financial information via the utility of the decision characterizes the value relevance area of research, which attributes relevance to financial information if it presents a predicted and significant association with the share price (Barth et al., 2001; Holthausen \& Watts, 2001).

The seminal papers of Ball and Brown (1968) and Beaver (1968) are pioneering in the area of value relevance (Kothari, 2001). Based on the market efficiency proposition and by means of the investment decision reflected in the share price, Ball and Brown (1968) examined the utility of net income for investors. Share price behavior is used to verify utility since, given the market efficiency assumption, useful available financial information causes share price adjustments. The results of the research 
revealed that net income is useful and, therefore, relevant for decision making as it is related to share price. Beaver (1968) evaluated the informational content of earnings perceived by investors via their reaction to earnings announcements. The research was based on the premise that earnings that have informational content result in alterations in investors' valuations (share price) and behavior (share volume). The findings indicated that earnings have informational content, that is, the disclosure of earnings reports results in share price and volume reactions.

Given that relevance represents a fundamental qualitative characteristic for the utility of financial information and comparability represents a qualitative characteristic of improvement responsible for providing greater utility to relevant and faithful information, a relationship between relevance and comparability is possible (IASB, 2018a).

The Basis for Conclusions takes a position with respect to the criticisms regarding the distinction between fundamental qualitative characteristics and those of improvement, highlighting that relevant and faithful financial information can be useful, despite not fulfilling the characteristics of improvement. Moreover, it reveals that, despite comparability having been considered just as important as relevance and faithful representation for the 1989 framework, it is secondary, since comparable information may not be useful for decision making if it is not relevant or faithful (IASB, 2018b). That is, the qualitative characteristics of improvement, including comparability, may not make information useful if it is not relevant or faithful (IASB, 2018a).

Schipper (2003) discusses the possibility of a trade-off between comparability and predictive ability, one of the aspects of relevance, and states that prioritizing predictive ability can sacrifice comparability. For Schipper and Vincent (2003), prioritizing comparability can result in suboptimal treatments from a relevance viewpoint.

Simmons (1967) highlights the importance of research in relation to investigating both comparability and relevance for maximizing the utility of financial statements, given that comparability on its own is not responsible for maximizing the utility of financial statements. Schipper and Vincent (2003) identify the existence of a gap regarding the analysis of the achievement of comparability to the detriment of relevance.

With regard to the research that simultaneously covers relevance and comparability, Kim et al. (2018) investigated the contexts, reproduced through specific factors of users related to investor sophistication and informational asymmetry, under which the strength of the association between comparability and relevance is improved, that is, under which comparability promotes increased relevance. For relevance, the short window ERC was used as a measure of information utility; for comparability, adaptions of the measure from DeFranco et al. (2011) were used.

Kim et al. (2018) identified a positive relationship between comparability and relevance by means of the greater reaction to a unit of earnings news and increased significance of the ERC for a high level of comparability. This relationship is stronger for companies with greater investor sophistication and lower informational asymmetry. Moreover, they verified that the size of the adjustments of the analysts' forecasts regarding future performance is positively related to comparability, and that relationship is more pronounced for greater investor sophistication and lower informational asymmetry.

To examine whether comparability impacts the informativeness of share prices regarding future earnings, Choi et al. (2019) assumed that more comparable accounting statements make share prices more informative, given that they help investors in evaluating the relative status and performance of companies in relation to their peers and in assessing the way economic events are translated into the accounting numbers. Informativeness was measured using the FERC, which enables an analysis of how well current share prices or returns, which express market expectations, anticipate the achievement of future earnings. For comparability, in turn, adaptations were applied to the measure from DeFranco et al. (2011).

The results of Choi et al. (2019) reported that comparability promotes better informativeness of the share price about future earnings and better anticipation of future earnings news. The research indicates that comparability enables a better reflection of the specific earnings of companies in share prices in relation to sector or market earnings and a greater amount of specific information on companies portrayed in share prices. Thus, Choi et al. (2019) recognize that comparability results in better decision making regarding the allocation of capital and in a lower cost of collecting and processing specific company information.

\subsection{Development of the Research Hypotheses}

This study conjectures that comparability provides an improvement in relevance, given that relevance is fundamental for the utility of financial reports and comparability is responsible for improving the respective 
utility. That is, comparability would enable greater relevance by achieving greater utility of financial reports (IASB, 2018a). Moreover, the studies of Choi et al. (2019) and Kim et al. (2018) indicated a positive relationship between comparability and relevance and revealed that comparability enables a better understanding and assessment of the financial performance of companies in relation to their peers, as well as more appropriate inferences regarding how economic events are translated into numbers in financial statements.

Due to the confusion between the concepts of uniformity and comparability for financial information users, it is important to investigate the "effectiveness" of uniformity regarding the utility of the decision via its relationship with the qualitative characteristic of relevance (Caylor et al., 2018). Although May (1938) suggests that uniformity makes accounts more valuable, this study hypothesizes that uniformity is negatively related with relevance due to the absence of variation in the preparation and presentation of financial statements resulting in similar treatments for different economic circumstances, hindering comparability and the utility of users' capital allocation decisions. It is assumed that uniformity, unlike comparability, makes it difficult to assess the performance of companies in relation to their peers from the same sector classification by not enabling investors to identify whether the differences in company performance originate from differences in the mapping of underlying economic events or from differences in economic fundamentals (Choi et al., 2019).

Despite the hypothesis that uniformity is negatively related to relevance, this study presupposes that uniformity becomes positively related to relevance when it contributes to comparability. Hendriksen (1967, p. 106) suggests that uniformity does not correspond to a goal of financial reports and "may only be relevant insofar as it can contribute to obtaining comparability," and Simmons (1967) reveals that comparability represents the goal of financial reports and uniformity is partially compatible with that goal by producing comparability in some situations, though not in all. In light of this, the research hypothesis is that the comparability of financial reports provides greater relevance for the Brazilian capital market and the uniformity of financial reports only provides greater relevance when it contributes to comparability. The operational hypotheses are:

\begin{abstract}
$\mathrm{H}_{1}$ : the uniformity of companies' financial reports in relation to their peers from the same sector classification is negatively related to the relevance for the Brazilian capital market.

$\mathrm{H}_{2}$ : the uniformity of companies' financial reports in relation to their peers from the same sector classification is positively related to the relevance for the Brazilian capital market when it contributes to comparability.

$\mathrm{H}_{3}$ : the comparability of companies' financial reports in relation to their peers from the same sector classification is positively related to the relevance for the Brazilian capital market.
\end{abstract}

The investigation of the hypotheses seeks to fill research gaps presented by Caylor et al. (2018) with respect to verifying the "effectiveness" of uniformity by means of the relationship between it and the qualitative characteristic of relevance, and by Simmons (1967) and Schipper and Vincent (2003), respectively, regarding investigating both comparability and relevance for maximizing the utility of financial statements and analyzing the achievement of comparability to the detriment of relevance.

\section{METHODOLOGICAL PROCEDURES}

\subsection{Research Models}

\subsubsection{Uniformity}

Uniformity is determined by means of the earnings covariance measure, which captures earnings similarities without acknowledging the similarities of economic events and of the underlying economy (Lang et al., 2010; Ribeiro et al., 2016b). To measure uniformity under earnings covariance it is necessary to estimate a time series regression of one company's earnings in accordance with the time series of the earnings of another company (equation 1) belonging to the same sector classification (Ribeiro et al., 2016b):

$$
\text { Earnings }_{i t}=\Phi_{0 i j}+\Phi_{1 i j} \text { Earnings }_{j t}+\varepsilon_{i j t}
$$

in which Earnings it $_{\mathrm{it}}$ is the unconsolidated net earnings of company $i$ for quarter $t$, Earnings $s_{\mathrm{jt}}$ is the unconsolidated net earnings of company $j$ for quarter $t, \Phi_{0 i j}$ is the intercept, and $\Phi_{1 j}$ is the inclination coefficient of the Earnings $s_{\mathrm{jt}}$ variable.

The earnings covariance uniformity measure is translated by means of the coefficient of determination 
of the time series regression $\left(\mathrm{R}^{2}\right)$ of the earnings of company $i$ in accordance with the time series of the earnings of company $j$. The interpretation is carried out such that the higher the $\mathrm{R}^{2}$ of the regression, the greater the uniformity between companies $i$ and $j$. Similarly to that of DeFranco et al. (2011), the regression estimation covers the last 16 quarters (four years).

Given that the uniformity measure $\left(\mathrm{R}^{2}\right)$ of equation 1 reproduces a relative measure, that is, the uniformity of company $i$ in relation to company $j$, the coefficients of determination are calculated for the different possible combinations of pairs of companies belonging to the same sector classification. The individual uniformity is portrayed by the mean of the estimated coefficients of determination of the possible pairs of companies (equation 2):

$$
M U N I F_{i t}=\frac{\sum R_{i j t}^{2}}{n}
$$

in which $M U N I F_{\text {it }}$ is the mean individual uniformity measure of company $i$ in relation to the peer companies from the same sector classification for period $t, R_{\mathrm{ijt}}^{2}$ is the uniformity measure related to each pair of companies belonging to the same sector classification for period $t$, and $n$ is the number of possible pair combinations of company $i$ in relation to the companies belonging to the same sector classification.

\subsubsection{Comparability}

Comparability is identified using the accounting function similarity measure proposed by DeFranco et al. (2011) with adaptations already used in the studies of Reina et al. (2019), Ribeiro et al. (2016a, 2016b), and Yip and Young (2012). This measure is adopted to make viable the data collection for the analysis period and because it is based on output that does not require, unlike inputbased measures, the selection and weighting of accounting choices. Fields et al. (2001) address the existence of multiple choices regarding accounting methods and highlight that investigating a single choice can obscure the general effect of a portfolio of accounting choices. Gross and Perotti (2017) present four benefits for the output-based measures in relation to the input-based ones: greater relevance for users, since the focus is the output; greater objectivity, as they do not require the selection and weighting of inputs; greater ease of application, due to the availability of data; and greater precision of the comparability measurement with the control of the similarity of economic events.

Thus, the accounting function similarity measure better reflects the weighting of the accounting choices used by companies when calculating earnings, it enables the collection of data on a bigger set of accounting choices by using financial and return data that are publically available, it is more relevant for users, and it is more precise for measuring comparability (DeFranco et al., 2011; Gross \& Perotti, 2017).

The accounting function similarity measure from DeFranco et al. (2011) is based on the definition of an accounting system, such as the mapping of economic events for financial statements, and it considers accounting systems to be comparable when, for a given set of economic events, similar financial statements are presented.

The first stage for the comparability measure corresponds to estimating the accounting function of each company. In the same way as Reina et al. (2019), Ribeiro et al. (2016a, 2016b), and Yip and Young (2012), equation 3 presents some adaptations: the substitution of the use of quarterly net income before extraordinary items (operational) by net income, given that the latter is widely available and more comprehensive in relation to the accounting choices, and the substitution of market value by assets to deflate net income. The aforementioned authors indicate that these adaptations did not produce any bias in relation to the original measure proposed by DeFranco et al. (2011). However, it should be noted that using net operating income over assets instead of net income over assets could lead to differences in the results. Similarly to the measure of DeFranco et al. (2011), the individual accounting function estimation considers the last 16 quarters (four years):

$$
R O A_{i t}=\alpha_{i}+\beta_{i} \text { Return }_{i t}+\varepsilon_{i t}
$$

in which $R O A_{\text {it }}$ is the ratio between the unconsolidated quarterly net income and total assets at the end of the financial period of company $i$ for quarter $t$, Return $_{\mathrm{it}}$ is the mean quarterly share return of company $i$ for quarter $t$, calculated using the closing price of the shares and adjusted by proceeds, including dividends, $\alpha_{i}$ is the intercept, and $\beta_{\mathrm{i}}$ is the inclination coefficient of the Return ${ }_{\mathrm{it}}$ variable.

Due to comparability being a "proximity" measure of the accounting functions, after estimating the individual parameters it is necessary to estimate the ROA for two companies belonging to the same sector classification, considering that these have experienced similar economic events and, therefore, present the same share return:

$$
\begin{aligned}
& E(R O A)_{i i t}=\hat{\alpha}_{i}+\hat{\beta}_{i} \text { Return }_{i t} \\
& E(R O A)_{i j t}=\hat{\alpha}_{j}+\hat{\beta}_{j} \text { Return }_{i t}
\end{aligned}
$$


in which $E(R O A)_{\text {iit }}$ is the predicted ROA of company $i$ with the individual parameters of the accounting function of company $i$ and the return of company $i$ for quarter $t$ and $E(R O A)_{\mathrm{ijt}}$ is the predicted ROA of company $j$ with the individual parameters of the accounting function of company $j$ and the return of company $j$ for quarter $t$.

Consequently, the accounting comparability is translated by the negative value of the mean absolute difference of the predicted ROAs of companies $i$ and $j$. The interpretation of the comparability measure of DeFranco et al. (2011) is carried out such that the highest values indicate greater accounting comparability for the pairs of companies belonging to the same sector. To produce this interpretation, the mean distance of the results calculated for the estimated ROAs of companies $i$ and $j$ in equations 4 and 5 should be multiplied by -1 :

$$
\operatorname{Comp}_{i j t}=-\frac{1}{16} \times \sum_{t-15}^{t}\left|E\left(R O A_{i i t}\right)-E\left(R O A_{i j t}\right)\right|
$$

in which Comp $p_{\mathrm{ijt}}$ is the comparability measure relating to company $i$ based on company $j$ for period $t$.

Since the comparability measure of equation 6 represents a relative measure, that is, the comparability of company $i$ in relation to company $j$, the comparability measures are calculated for the different possible combinations of pairs of companies belonging to the same sector classification and the individual comparability is calculated using the mean of the distances between these companies (equation 7):

$$
\operatorname{MCOMP}_{i t}=\frac{\sum \operatorname{Comp}_{i j t}}{n}
$$

in which $M C O M P_{\mathrm{it}}$ is the mean individual comparability measure of company $i$ in relation to the peer companies from the same sector classification for period $t, \operatorname{Comp}_{\mathrm{ijt}}$ is the relative comparability measure of each pair of companies belonging to the same sector classification for period $t$, and $n$ is the number of possible pair combinations of company $i$ in relation to the companies belonging to the same sector classification.

\subsubsection{Relevance}

To fulfill the general objective and investigate the hypotheses, four relevance models are proposed under the decision utility perspective (IASB, 2018a; Scott, 2015), which characterizes the value relevance area, in which financial information is considered relevant for the capital market when it is significantly related to the share price (Barth et al., 2001; Beaver, 2002; Holthausen \& Watts, 2001). The seminal papers of Ball and Brown (1968) and Beaver (1968) used the alteration in share price to identify the utility and informational content of financial information.

The assessment model repeatedly applied in the value relevance research is presented by Ohlson (1995) and portrays the market value of shares by means of a linear function of the book value of net earnings and present value of expected future abnormal earnings. The respective model, derived from the residual revenue evaluation and dividends evaluation, is based on the clean surplus assumption and is adapted by Collins et al. (1997) to remove the term that discounts earnings, as this does not significantly improve the explanatory power (Barth et al., 2001; Beaver, 2002; Collins et al., 1997; Ohlson, 1995).

Equations 8 to 11 are based on the Ohlson (1995) model adapted by Collins et al. (1997) and employ the share price as the dependent variable and net equity and net income as control variables. For the dependent variable, the companies' share price three months after the end of the financial period is considered, in order to ensure the disclosure of the financial statements, given that in this period these are disclosed and the information forms part of the share price and, consequently, market value (Barth, 1994):

$$
\begin{gathered}
P_{i t}=\alpha_{0}+\beta_{1} N E_{i t}+\beta_{2} N I_{i t}+\varepsilon_{i t} \\
P_{i t}=\alpha_{0}+\beta_{1} N E_{i t}+\beta_{2} N I_{i t}+\beta_{3} M U N I F_{i t}+\varepsilon_{i t} \\
P_{i t}=\alpha_{0}+\beta_{1} N E_{i t}+\beta_{2} N I_{i t}+\beta_{3} M U N I F x M C O M P_{i t}+\varepsilon_{i t} \\
P_{i t}=\alpha_{0}+\beta_{1} N E_{i t}+\beta_{2} N I_{i t}+\beta_{3} M C O M P_{i t}+\varepsilon_{i t}
\end{gathered}
$$

in which $\alpha$ is the intercept, $\beta$ is the inclination coefficient of the independent variable, $P_{\mathrm{it}}$ is the share price of company $i$ three months after the end of period $t, N E_{\mathrm{it}}$ is the unconsolidated net equity at the end of the period divided by the number of shares of company $i$ for period $t, N I_{\text {it }}$ is the unconsolidated net income at the end of the period divided by the number of shares of company $i$ for period $t, M U N I F_{\text {it }}$ is the mean individual uniformity measure of each company in relation to the peer companies from the same sector classification for period $t, M C O M P_{\text {it }}$ is the mean individual comparability measure of each company in relation to the peer companies from the same sector classification for period $t$, and $\varepsilon_{\mathrm{it}}$ is the error.

Hypotheses $\mathrm{H}_{1}, \mathrm{H}_{2}$, and $\mathrm{H}_{3}$ are analyzed using the statistical significance and, subsequently, the sign of the coefficient of the explanatory variables: uniformity (equation 9), uniformity and comparability multiplication 
(equation 10), and comparability (equation 11). Moreover, the explanatory powers of equations 9 to 11 are compared to the explanatory power of equation 8 , which does not include the explanatory variables.

\subsection{Study Sample and Data Collection}

To choose the initial study sample, we considered publicly-traded companies listed on the B3 S.A. - Brasil, Bolsa, Balcão (B3) belonging to sectors classified in Level 2 of the North American Classification System (NAICS) that comprise at least two companies. Level 2 of the NAICS has already been employed in sector comparability studies (DeFranco et al., 2011; Lang et al., 2010; Reina et al., 2019; Ribeiro et al., 2016a, 2016b; Yip \& Young, 2012). After eliminating 16 Level 2 NAICS sectors for only including one company (16 companies) and eliminating four companies due to the absence of a sector classification, the initial sample was composed of 41 Level 2 NAICS sectors and 332 companies.

The secondary data of the initial sample were collected in the Economatica ${ }^{\circledR}$ software for the period covering 2010 to 2018 , but the uniformity, comparability, and, consequently, relevance of these variables were analyzed for the periods from 2013 to 2018, given that the uniformity and comparability measures adapted from DeFranco et al. (2011) and Lang et al. (2010) consider the last 16 quarters (four years) for the regression estimation.

Similarly to Ribeiro et al. (2016a, 2016b), uniformity and comparability are calculated individually for the companies, that is, without considering the economic group. Consequently, the variables of this study, including those of the value relevance models, are represented by unconsolidated values. It is important to highlight that for the mean quarterly share return and share price variables the companies' preference shares are used.

The impossibility of calculating uniformity, due to the absence of quarterly net income in the Economatica ${ }^{\circledR}$ software, led to the elimination of 27 companies and two sectors. In turn, the impossibility of calculating comparability, resulting from the absence of quarterly ROA and/or mean quarterly share return, led to the elimination of 175 companies and eight sectors. Thus, the final sample for uniformity is composed of 305 companies belonging to 39 sectors and for comparability it is composed of 157 companies belonging to 33 sectors.

The absence of a uniformity value due to the impossibility of calculating it led to the exclusion of 113 observations and the absence of a share price led to the exclusion of 493 observations. In light of this, the sample for the relevance of uniformity is composed of 1,224 observations represented by 246 companies (equation 9 ).
Since all the observations that include values for comparability simultaneously contain values for uniformity, the sample for the relevance of uniformity as a contributor to comparability (equation 10) and the sample for the relevance of comparability (equation 11) are similar. The absence of a comparability value, due to the impossibility of calculating it, led to the exclusion of 1,066 observations. The resulting 764 observations presented an amount for the dependent variable share price. Therefore, the sample for the relevance of uniformity as a contributor to comparability (equation 10) and the sample for the relevance of comparability (equation 11) are composed of 764 observations represented by 157 companies.

\subsection{Statistical Approach}

The research hypotheses are analyzed using the panel data regression model statistical approach. The proposed panel is identified as short and unbalanced (Fávero et al., 2014). The statistical analyses for the period from 2013 to 2018 were carried out using the Stata ${ }^{\circledR}$ software.

The descriptive statistics of the MUNIF and MCOMP variables and of the variables of the relevance model suggested the presence of outliers, primarily due to the considerable distances between the minimum and maximum. Therefore, prior to the following statistical analyses, we applied the multivariate treatment, produced by Hadi (1992), to identify outliers in the data. The outliers were excluded from the analyses and statistical results of this study so that the discrepant data do not compromise the results.

Prior to any estimation, we analyzed the behavior of the variance of the variables over time for a respective individual (within variance) and between individuals for each cross section (between variance). It was perceived that the between variance is greater than the within variance both for the dependent variable and for the explanatory variables. That is, fixed effects estimation is not appropriate and the results of the preliminary variance diagnostic indicate that random effects estimation is more appropriate.

Subsequently, the Breusch-Pagan Lagrange Multiplier (LM), Chow, and Hausman tests were applied to identify the most appropriate panel data model for this research. The p-value results of the tests revealed that the random effects model was most appropriate and robust for all the equations, which supports the preliminary diagnostic. It is important to highlight that the regressions are estimated with the option of robust standard errors clusterized by individual to limit heteroscedasticity problems (Hoechle, 2007). 


\section{PRESENTATION AND ANALYSIS OF THE RESULTS}

\subsection{Descriptive Statistics}

Table 1 presents the descriptive statistics for the MUNIF and MCOMP variables.

Table 1

Descriptive statistics for the mean individual uniformity (MUNIF) and mean individual comparability (MCOMP) variables

\begin{tabular}{|c|c|c|c|c|c|c|c|}
\hline Period & 2013 & 2014 & 2015 & 2016 & 2017 & 2018 & General \\
\hline \multicolumn{8}{|c|}{ MUNIF } \\
\hline $\mathrm{N}$ & 267 & 277 & 281 & 286 & 287 & 287 & 1.685 \\
\hline Mean & 0.11061 & 0.11497 & 0.12156 & 0.12526 & 0.11781 & 0.10896 & 0.11659 \\
\hline $\begin{array}{l}\text { Standard } \\
\text { deviation }\end{array}$ & 0.06931 & 0.07471 & 0.08503 & 0.09143 & 0.07967 & 0.07628 & 0.07994 \\
\hline Minimum & 0.00137 & 0.00054 & 0.00214 & 0.00105 & 0.0032 & 0.00219 & 0.00054 \\
\hline Maximum & 0.40832 & 0.42368 & 0.40856 & 0.44887 & 0.43769 & 0.42311 & 0.44887 \\
\hline \multicolumn{8}{|c|}{ MCOMP } \\
\hline $\mathrm{N}$ & 109 & 109 & 110 & 111 & 123 & 119 & 681 \\
\hline Mean & -2.97079 & -3.71166 & -3.20032 & -3.79132 & -3.65527 & -3.39488 & -3.45793 \\
\hline $\begin{array}{l}\text { Standard } \\
\text { deviation }\end{array}$ & 2.54033 & 2.89171 & 2.18009 & 2.96032 & 2.73787 & 2.64924 & 2.67959 \\
\hline Minimum & -12.71556 & -13.34296 & -11.14165 & -13.2578 & -13.97874 & -13.82101 & -13.97874 \\
\hline Maximum & -0.48729 & -0.56217 & -0.58505 & -0.19852 & -0.17546 & -0.2871 & -0.17546 \\
\hline
\end{tabular}

Source: Elaborated by the authors.

The mean of the MUNIF variable is relatively close to that of the study of Ribeiro et al. (2016b). In that respective study, the earnings covariance measure presented a mean of 0.145 for the analysis period covering 2004 to 2012 . The study of Lang et al. (2010), in turn, recorded means of 0.358 for companies not adopting the International Financial Reporting Standards (IFRS) and 0.364 for companies adopting the IFRS. As already indicated by Ribeiro et al. (2016b), the mean uniformity in the international context is more than triple the Brazilian mean.

With regard to the analysis of the descriptive statistics by period, relative stability of the MUNIF variable is perceived via the mean. Despite the relative stability, for the MUNIF variable a slight tendency for growth is identified from 2013 to 2016 and a slight decreasing trend as of 2016. It is noted that the MUNIF variable presented higher means for the period of economic recession in Brazil (2014 to 2016) in relation to the 2013 period. The highest mean is recorded in 2016 . This may be explained by a possible greater similarity in the earnings variances - an aspect captured in the earnings covariance measure of Lang et al. (2010) - for periods of economic recession, since the negative influence is perceived in a similar way for the whole capital market, especially for pairs of companies belonging to the same sector classification.

The mean of the MCOMP variable is lower than the means presented in the studies of Ribeiro et al. (2016b) and Reina et al. (2019) of -2.634 and -1.09 , respectively. Lang et al. (2010) identified a mean individual comparability of -0.310 for companies not adopting the IFRS and -0.184 for those adopting the IFRS.

In the studies of Choi et al. (2019), DeFranco et al. (2011), and Kim et al. (2018), comparability is also measured by the similarity of the accounting function. However, while individual comparability in this study is recognized via the mean of the relative comparability measures, that of the aforementioned studies is portrayed via the median of the relative comparability measures. Thus, it is important to note the methodological differences when comparing the result of the MCOMP variable to the results of the respective studies. The means for individual comparability presented by DeFranco et al. (2011), Kim et al. (2018), and Choi et al. (2019) are -2.5, -2.316, and -1.711 , respectively, that is, higher than the mean for the MCOMP variable in this study (-3.45793). 
The mean of the MCOMP variable is close to the one indicated in the study of Caylor et al. (2018), of -3.64 for the analysis period from 2000 to 2016. However, the methodology used for calculating individual comparability in relation to relative comparability was not identified.

With respect to the analysis of the descriptive statistics by period, via the mean, reductions are found from 2013 to 2014 and from 2015 to 2016 and rises from 2014 to 2015 and from 2016 to 2018 . The reduction in the mean for individual comparability from 2013 to 2014 and the rise from 2014 to 2015 are also recorded in the study of Reina et al. (2019).

Despite the growth in the MCOMP variable, Table 1 shows a reduction in the respective variable for the analysis period (2013 to 2018) by designating 2013 as a parameter. One possible explanation for this perception, together with the lower mean of the MCOMP variable in relation to the studies of Reina et al. (2019) and Ribeiro et al. (2016b), is that the analysis period includes the economic recession recorded from 2014 to 2016 in Brazil. The recession may have impacted comparability due to the accounting function similarity measure using the mean share return of the companies, which was probability sensitive to the economic recession (Ribeiro et al., 2016a). Moreover, the economic recession probably influenced the companies' individual economic circumstances and, as a result, the reflection of those circumstances, which represents the comparability (Simmons, 1967).

The mean of the MCOMP variable presented a small rise from 2016 to 2018 , periods subsequent to the economic recession; however, it was still lower than the mean recorded in 2013. The permanence of the lower mean MCOMP in relation to the 2013 parameter may be related to the slow recovery from the economic recession in Brazil (Graner, 2020).

The simultaneous analysis of the descriptive statistics of the MUNIF and MCOMP variables signals the presence of differences in the behaviors of the variables, since, for example, 2016 records the highest mean for the MUNIF variable (0.12526) and, in contrast, the lowest mean for the MCOMP variable (-3.79132) (Table 1), and while the MUNIF variable tends to fall as of 2016, the MCOMP variable shows a rising trend for a similar period. Moreover, in relation to the 2013 parameter, for the period of economic recession in Brazil (2014 to 2016), the MUNIF variable presents higher means and the MCOMP variable presents lower means. That is, the influence of the economic recession is likely to be different for the two variables. Ribeiro et al. (2016b) find statistically significant differences between the behavior of uniformity and that of comparability for the period from 2005 to 2012.

The difference in the behaviors of the variables portrays the conceptual distinction between uniformity and comparability and, complementarily, it reflects the distinction between the measures themselves. The earnings covariance measure captures similarities in earnings without considering the similarity of economic events (Lang et al., 2010; Ribeiro et al., 2016b). The accounting function similarity measure, in turn, is based on the conception of the similarity of economic events and the equivalent reflection of the economic circumstances (DeFranco et al., 2011; Simmons, 1967).

\subsection{Relevance of Uniformity and of Comparability}

Table 2 shows the descriptive statistics for the variables of the relevance models.

\section{Table 2}

Descriptive statistics of the variables of the relevance models

\begin{tabular}{|c|c|c|c|c|c|}
\hline Variable & $\mathbf{N}$ & Mean & Standard deviation & Minimum & Maximum \\
\hline \multicolumn{6}{|c|}{$P_{\mathrm{it}}=\alpha_{0}+\beta_{1} N E_{\mathrm{it}}+\beta_{2} N I_{\mathrm{it}}+\beta_{3} M U N I F_{\mathrm{it}}+\varepsilon_{\mathrm{it}}($ equation 9) } \\
\hline $\mathrm{P}$ & 1.051 & 13.67829 & 11.39947 & 0.00391 & 61.10815 \\
\hline $\mathrm{NE}$ & 1.051 & 11.19948 & 11.96531 & -41.22084 & 66.10306 \\
\hline $\mathrm{NI}$ & 1.051 & 0.82223 & 2.01765 & -7.70807 & 10.54925 \\
\hline MUNIF & 1.051 & 0.12377 & 0.09509 & 0.00054 & 0.54339 \\
\hline \multicolumn{6}{|c|}{$P_{\mathrm{it}}=\alpha_{0}+\beta_{1} N E_{\mathrm{it}}+\beta_{2} N \mathrm{lit}_{\mathrm{it}}+\beta_{3} M U N I F x M C O M P_{\mathrm{it}}+\varepsilon_{\mathrm{it}}($ equation 10) } \\
\hline $\mathrm{P}$ & 617 & 13.52538 & 10.24952 & 0.00391 & 61.10815 \\
\hline $\mathrm{NE}$ & 617 & 11.46452 & 10.92514 & -41.22084 & 58.58801 \\
\hline $\mathrm{NI}$ & 617 & 0.8471 & 1.85694 & -7.70807 & 7.69407 \\
\hline MUNIF×MCOMP & 617 & -0.40024 & 0.39386 & -2.28104 & -0.00037 \\
\hline
\end{tabular}


Table 2

Cont.

\begin{tabular}{cccccc}
\hline Variable & $\mathbf{N}$ & Mean & Standard deviation & Minimum & Maximum \\
\hline \multicolumn{7}{c}{$P_{\mathrm{it}}=\alpha_{0}+\beta_{1} N E_{\mathrm{it}}+\beta_{2} N l_{\mathrm{it}}+\beta_{3} M C O M P_{\mathrm{it}}+\varepsilon_{\mathrm{it}}($ equation 11$)$} \\
\hline $\mathrm{P}$ & 605 & 13.49111 & 10.08761 & 0.00391 & 57.33266 \\
\hline $\mathrm{NE}$ & 605 & 11.54259 & 10.64398 & -16.7191 & 58.58801 \\
\hline $\mathrm{NI}$ & 605 & 0.8432 & 1.85022 & -7.70807 & 7.69407 \\
\hline MCOMP & 605 & -3.34111 & 2.67319 & -16.08592 & -0.17546 \\
\hline
\end{tabular}

Source: Elaborated by the authors.

From Table 2 it can be noted that the mean is lower than the standard deviation (SD) for the NE variable in equation 9 and for the NI variable in equations 9 to 11 . Despite excluding the outliers in the presentation of the descriptive statistics, high SDs are recorded, especially for the $\mathrm{P}$ and NE variables, as well as expressive distances between the minimum and maximum, especially for the $\mathrm{P}, \mathrm{NE}$, and NI variables.

Prior to running the panel data regressions, it is essential to examine the correlation matrix of the variables to detect indications of the presence of multicollinearity.
The respective matrix presents statistical evidence of the possible absence of multicollinearity due to the correlations between the explanatory variables not exceeding 0.8 , the parameter presented by Fávero et al. (2014). Just as hypothesized in the study, the MUNIF variable is negatively correlated with the $\mathrm{P}$ variable $(\mathrm{p}$-value $=-0.0353)$ and the MUNIF $\times$ MCOMP ( $\mathrm{p}$-value $=0.0406)$ and MCOMP $(\mathrm{p}$-value $=0.0097)$ variables are positively correlated with the $\mathrm{P}$ variable, but these correlations are not significant.

The results of equations 8 and 9 for the analysis of $\mathrm{H} 1$ are revealed in Table 3.

Table 3

Results of the regression (relevance MUNIF)

\begin{tabular}{|c|c|c|c|c|c|c|c|}
\hline \multicolumn{4}{|c|}{$\mathrm{P}_{\mathrm{it}}=\alpha_{0}+\beta_{1} \mathrm{NE}_{\mathrm{it}}+\beta_{2} \mathrm{NI}_{\mathrm{it}}+\beta_{3} \mathrm{MUNIF}_{\mathrm{it}}+\varepsilon_{\mathrm{it}}$ (equation 9) } & \multicolumn{4}{|c|}{$P_{i t}=\alpha_{0}+\beta_{1} N E_{i t}+\beta_{2} N I_{i t}+\varepsilon_{i t}$ (equation 8) } \\
\hline Variable & Coefficient & Z statistic & p-value & Variable & Coefficient & Z statistic & p-value \\
\hline \multicolumn{4}{|c|}{ Panel A } & \multicolumn{4}{|c|}{ Panel A } \\
\hline $\mathrm{NE}$ & 0.06645 & 1.30 & 0.193 & $\mathrm{NE}$ & 0.06635 & 1.30 & 0.195 \\
\hline $\mathrm{NI}$ & 0.93725 & 3.86 & 0.000 & $\mathrm{NI}$ & 0.93624 & 3.85 & 0.000 \\
\hline MUNIF & -2.01035 & -0.72 & 0.473 & & & & \\
\hline Constant & 12.79787 & 12.23 & 0.000 & Constant & 12.55205 & 13.80 & 0.000 \\
\hline \multicolumn{4}{|c|}{ Panel B } & \multicolumn{4}{|c|}{ Panel B } \\
\hline $\mathrm{R}^{2}$ within & 0.0400 & Wald chi & 21.65 & $\mathrm{R}^{2}$ within & 0.0399 & Wald chi & 19.79 \\
\hline$R^{2}$ between & 0.0647 & Prob $>$ chi $^{2}$ & 0.0001 & $\mathrm{R}^{2}$ between & 0.0626 & Prob $>$ chi $^{2}$ & 0.0001 \\
\hline $\mathrm{R}^{2}$ overall & 0.0912 & $\mathrm{~N}$ & 1.051 & $\mathrm{R}^{2}$ overall & 0.0891 & $\mathrm{~N}$ & 1.051 \\
\hline
\end{tabular}

Source: Elaborated by the authors.

The explanatory power of equation 9 indicates that $9.12 \%$ of the share price variability is explained by the joint variability of the explanatory variables. Moreover, the p-value of the Wald $\mathrm{Z}$ statistic confirms statistical significance for the panel data model and suggests that at least one of the coefficients of the independent variables is significant at the $1 \%$ level. With regard to the control variables of the Ohlson (1995) assessment model, with adaptations from Collins et al. (1997), NE did not show significance and, in contrast, NI showed significance at the $1 \%$ level and was positively related to the share price. The explanatory variable of interest
(MUNIF) did not show significance and, consequently, $\mathrm{H}_{1}$ is rejected.

Although the MUNIF variable is not relevant for the Brazilian capital market, the comparison of the overall $\mathrm{R}^{2}$ of equations 8 and 9 in Table 3 enables a 0.21 percentage point increase in explanatory power to be identified with the addition of the MUNIF variable. Similarly to equation 9 , for equation 8 , the NE variable did not show significance and the NI variable showed significance at the $1 \%$ level and was positively related to the share price.

The results of equations 8 and 10 for the analysis of $\mathrm{H}_{2}$ are reported in Table 4 . 
Table 4

Regression results (relevance MUNIF $\times M C O M P$ )

\begin{tabular}{|c|c|c|c|c|c|c|c|}
\hline \multicolumn{4}{|c|}{$P_{i t}=\alpha_{0}+\beta_{1} N E_{i t}+\beta_{2} N I_{i t}+\beta_{3} M U N I F x M C O M P_{i t}+\varepsilon_{i t}($ equation 10) } & \multicolumn{4}{|c|}{$P_{i t}=\alpha_{0}+\beta_{1} N E_{i t}+\beta_{2} N l_{i t}+\varepsilon_{i t}($ equation 8$)$} \\
\hline Variable & Coefficient & Z statistic & p-value & Variable & Coefficient & Z statistic & p-value \\
\hline \multicolumn{4}{|c|}{ Panel A } & \multicolumn{4}{|c|}{ Panel A } \\
\hline NE & 0.08148 & 1.20 & 0.230 & PL & 0.08415 & 1.25 & 0.212 \\
\hline $\mathrm{NI}$ & 0.96989 & 3.18 & 0.001 & RL & 0.97707 & 3.21 & 0.001 \\
\hline MUNIF×MCOMP & 0.62235 & 0.73 & 0.463 & & & & \\
\hline Constant & 12.31455 & 11.05 & 0.000 & Constant & 12.03689 & 12.07 & 0.000 \\
\hline \multicolumn{4}{|c|}{ Panel B } & \multicolumn{4}{|c|}{ Panel B } \\
\hline $\mathrm{R}^{2}$ within & 0.0428 & Wald chi & 18.86 & $\mathrm{R}^{2}$ within & 0.0419 & Wald chi $^{2}$ & 16.67 \\
\hline $\mathrm{R}^{2}$ between & 0.0928 & Prob $>$ chi $^{2}$ & 0.0003 & $\mathrm{R}^{2}$ between & 0.0905 & Prob $>$ chi $^{2}$ & 0.0002 \\
\hline $\mathrm{R}^{2}$ overall & 0.1002 & $\mathrm{~N}$ & 617 & $\mathrm{R}^{2}$ overall & 0.1003 & $\mathrm{~N}$ & 617 \\
\hline
\end{tabular}

Source: Elaborated by the authors.

The results of equation 10 indicate statistical significance for the panel data model and reveal that $10.02 \%$ of the share price variability is explained by the joint variability of the explanatory variables. The NE variable did not present significance and the NI variable presented significance at the $1 \%$ level and was positively related to the share price. For the explanatory variable of interest of equation 10 (MUNIF $\times$ MCOMP), no statistical significance was found, and so $\mathrm{H}_{2}$ is rejected.
The overall $\mathrm{R}^{2}$ of equation 8 in Table 4 indicates that including the MUNIF $\times$ MCOMP variable results in a 0.01 percentage point decrease in explanatory power. Similarly to equation 10 , the NE variable did not present significance and the NI variable presented significance at the $1 \%$ level and was positively related to the share price.

The results of equations 8 and 11 for the analysis of $\mathrm{H}_{3}$ are shown in Table 5 .

Table 5

Regression results (relevance MCOMP)

\begin{tabular}{|c|c|c|c|c|c|c|c|}
\hline \multicolumn{4}{|c|}{$P_{i t}=\alpha_{0}+\beta_{1} N E_{i t}+\beta_{2} N I_{i t}+\beta_{3} M C O M P_{i t}+\varepsilon_{i t}($ equation 11) } & \multicolumn{4}{|c|}{$P_{i t}=\alpha_{0}+\beta_{1} N E_{i t}+\beta_{2} N l_{i t}+\varepsilon_{i t}($ equation 8$)$} \\
\hline Variable & Coefficient & Z statistic & p-value & Variable & Coefficient & Z statistic & p-value \\
\hline \multicolumn{4}{|c|}{ Painel A } & \multicolumn{4}{|c|}{ Panel A } \\
\hline NE & 0.08727 & 1.22 & 0.222 & PL & 0.09645 & 1.35 & 0.177 \\
\hline $\mathrm{NI}$ & 0.88034 & 3.17 & 0.002 & RL & 0.88431 & 3.11 & 0.002 \\
\hline MCOMP & 0.28413 & 1.96 & 0.050 & & & & \\
\hline Constant & 13.22318 & 10.61 & 0.000 & Constant & 12.14684 & 11.55 & 0.000 \\
\hline \multicolumn{4}{|c|}{ Painel B } & \multicolumn{4}{|c|}{ Panel B } \\
\hline $\mathrm{R}^{2}$ within & 0.0499 & Wald chi ${ }^{2}$ & 22.59 & $\mathrm{R}^{2}$ within & 0.0364 & Wald $\mathrm{chi}^{2}$ & 16.06 \\
\hline $\mathrm{R}^{2}$ between & 0.0646 & Prob $>$ chi $^{2}$ & 0.0000 & $\mathrm{R}^{2}$ between & 0.0818 & Prob $>$ chi $^{2}$ & 0.0003 \\
\hline $\mathrm{R}^{2}$ overall & 0.0787 & $\mathrm{~N}$ & 605 & $\mathrm{R}^{2}$ overall & 0.0922 & $\mathrm{~N}$ & 605 \\
\hline
\end{tabular}

Source: Elaborated by the authors.

From the interpretation of the explanatory power of equation $11,7.87 \%$ of the share price variability is explained by the joint variability of the explanatory variables. The $\mathrm{p}$-value of the Wald $\mathrm{Z}$ statistic supports statistical significance for the panel data models of equation 11. With regard to the control variables, NE did not show significance and NI showed significance at the $1 \%$ level and was positively related to the share price. The explanatory variable MCOMP showed significance at the $10 \%$ level and was positively related to the share price. Thus, $\mathrm{H}_{3}$ is not rejected and it is found that the mean individual comparability (MCOMP) is relevant for the Brazilian capital market and positively related to the share price.

The comparison of the overall $\mathrm{R}^{2}$ of equation 11 and of the overall $\mathrm{R}^{2}$ of equation 8 , in Table 5 , shows that despite the MCOMP variable being relevant, including the respective variable in the relevance model based on 
Ohlson (1995), with adaptations from Collins et al. (1997), leads to a 1.35 percentage point decrease in explanatory power. Similarly to equation 11, in equation 8 the NE variable did not show significance and the NI variable showed significance at the $1 \%$ level and was positively related to the share price.

The results of equations 8 to 11 reveal that NE is not relevant for the Brazilian capital market as it did not show a significant relationship with the share price. The absence of statistical significance for NE may be explained by the analysis period of the research (2013 to 2018) covering IFRS adoption (Brunozi et al., 2017; Macedo et al., 2013; Santos et al., 2019) and including periods of economic recession and political crisis (2014 to 2016) (Macedo et al., 2013). The economic recession and political crisis may have caused a detachment between the companies' financial situation and the behavior of the capital market given the difficulty for net equity to accompany the share price because of its constrained volatility and in light of the greater relevance of exogenous variables recorded in some periods (Macedo et al., 2013).

\section{CONCLUDING REMARKS}

This study set the aim of analyzing the relationship between the characteristics of uniformity and comparability and the fundamental qualitative characteristic of relevance of financial reports for the Brazilian capital market. Uniformity, identified through the earnings covariance measure from Lang et al. (2010), presented a mean result close to that of the study of Ribeiro et al. (2016b) and approximately three times lower than in the study of Lang et al. (2010). Comparability, in turn, identified using the mean of the accounting function similarity measure from DeFranco et al. (2011), portrayed a lower mean result than the national studies of Reina et al. (2019) and Ribeiro et al. (2016b) and the international ones of Choi et al. (2019), DeFranco et al. (2011), and Kim et al. (2018).

One possible explanation for the lower mean comparability in relation to the national studies of Reina et al. (2019) and Ribeiro et al. (2016b) is the analysis period (2013 to 2018) including the economic recession in Brazil (2014 to 2016). The economic recession may have influenced the mean share return, applied in the accounting function similarity measure, and the companies' individual economic circumstances. In light of this, the reflection of the respective circumstances that is, comparability - is impacted (Simmons, 1967). This possible explanation may also be applied to the reduction in comparability identified in the analysis period through designating 2013 as a parameter. The means for comparability from 2017 and 2018 were still lower than the mean recorded in 2013. The maintenance of the lower mean comparability for these periods, in relation to the 2013 parameter, may be related to the slow recovery from the economic recession in Brazil (Graner, 2020).

It is important to highlight that uniformity, in contrast with comparability, revealed higher means for the period of economic recession in relation to the 2013 parameter.
This result may be explained by the possibility of greater similarity in the variations of earnings, given that the negative influence of the economic recession is perceived equally for the whole capital market, especially for pairs of companies from the same sector classification. The differences detected, including the adverse impacts in the recessionary periods, portray the distinction between uniformity and comparability.

With regard to the analysis of the relationship between uniformity and comparability, the results indicated that uniformity is not relevant for the Brazilian capital market. This may be explained by the possible production of superficial comparability, one of its dysfunctional aspects, and by the possible reduction in the utility of the financial information resulting from the application of similar accounting treatments for different economic arrangements or events, that is, resulting from uniformity (Gordon \& Gallery, 2012; Schipper, 2003; Zeff, 2007).

The assumption of Hendriksen (1967, p. 106) that uniformity "may only be relevant insofar as it can contribute to obtaining comparability" is not recognized in this study, as uniformity did not show relevance for the Brazilian capital market even when it was a contributor to comparability.

With regard to the analysis of the relationship between comparability and relevance, the results enable it to be verified that the comparability of financial reports is relevant for the Brazilian capital market. The significant and positive relationship detected between comparability and relevance is, in general, correlated with the findings of Choi et al. (2019) and Kim et al. (2018). It is deduced that, just as indicated in the respective studies, comparability provides a better understanding and assessment of the financial performance of companies in relation to their peers from the same sector classification and leads to more 
appropriate inferences of the translation of economic events into numbers for financial statements.

Despite the comparability of the financial reports showing relevance for the Brazilian capital market, the reduction in explanatory power with the inclusion of this variable in the relevance base model provides indications that comparability is achieved to the detriment of relevance (Schipper \& Vincent, 2003). It is important to highlight that the precedence of comparability for the application of accounting treatments that are not ideal from a relevance viewpoint is inconsistent with the Conceptual Structure as it violates the secondary role of comparability in relation to relevance (IASB, 2018a; Schipper \& Vincent, 2003).
There are inferences that the uniformity of financial statements is not relevant and, on the other hand, that comparability is relevant, and these inferences reveal that the Brazilian capital market captures the distinction between these concepts for company assessments.

For future research, we recommend covering periods prior to 2010 to analyze the relationship between the uniformity, comparability, and relevance of financial reports before and after IFRS adoption, covering periods of recovery from or the absence of an economic recession, applying different measures of uniformity and comparability, and adopting various methodologies for investigating the relevance of uniformity and comparability.

\section{REFERENCES}

American Institute of Certified Public Accountants. (1973). Objectives of financial statements. American Institute of Certified Public Accountants.

Ball, R., \& Brown, P. (1968). An empirical evaluation of accounting income numbers. Journal of Accounting Research, 6(2), 159-178.

Barth, M. E. (1994). Fair value accounting: Evidence from investment securities and the market valuation of banks. The Accounting Review, 69(1), 1-25.

Barth, M. E. (2013). Global comparability in financial reporting: What, why, how, and when? China Journal of Accounting Studies, 1(1), 2-12.

Barth, M. E., Beaver, W. H., \& Landsman, W. R. (2001). The relevance of the value relevance literature for financial accounting standard setting: Another view. Journal of Accounting and Economics, 31(1-3), 77-104.

Beaver, W. H. (1968). The information content of annual earnings announcements. Journal of Accounting Research, 6(2), 67-92.

Beaver, W. H. (2002). Perspectives on recent capital market research. The Accounting Review, 77(2), 453-474.

Brunozi, A. C., Jr., Ott, E., Coelho, D. M., Menegat, L. A., \& Webber, F. L. (2017). Persistência e value relevance dos resultados contábeis com a adoção das IFRS: um estudo em empresas de países do GLENIF. Enfoque: Reflexão Contábil, 36(3), 33-51.

Caylor, M., Chambers, D., \& Mutlu, S. (2018). Financial reporting uniformity: Its relation to comparability and its impact on financial statement users. https://papers.ssrn.com/sol3/papers. cfm?abstract_id=3221183

Chartered Financial Analyst. (2007). A comprehensive business reporting model: Financial reporting for investors. CFA Institute Centre for Financial Market Integrity.

Choi, J. H., Choi, S., Myers, L. A., \& Ziebart, D. (2019). Financial statement comparability and the informativeness of stock prices about future earnings. Contemporary Accounting Research, 36(1), 389-417.
Cole, V., Branson, J., \& Breesch, D. (2012). The uniformityflexibility dilemma when comparing financial statements: Views of auditors, analysts and other users. International Journal of Accounting \& Information Management, 20(2), 114-141.

Collins, D. W., Maydew, E. L., \& Weiss, I. S. (1997). Changes in the value-relevance of earnings and book values over the past forty years. Journal of Accounting and Economics, 24(1), 39-67.

DeFranco, G., Kothari, S. P., \& Verdi, R. S. (2011). The benefits of financial statement comparability. Journal of Accounting Research, 49(4), 895-931.

Fávero, L. P., Belfiore, P., Takamatsu, R. T., \& Suzart, J. (2014). Métodos quantitativos com Stata: procedimentos, rotinas e análise de resultados. Elsevier.

Fields, T. D., Lys, T. Z., \& Vincent, L. (2001). Empirical research on accounting choice. Journal of Accounting and Economics, 31(1-3), 255-307.

Gordon, I., \& Gallery, N. (2012). Assessing financial reporting comparability across institutional settings: The case of pension accounting. The British Accounting Review, 44(1), 11-20.

Graner, F. (2020). Recuperação é a mais lenta da história, destaca estudo. https://valor.globo.com/brasil/noticia/2020/02/20/ recuperacao-e-a-mais-lenta-da-historia-destaca-estudo.ghtml

Gross, C., \& Perotti, P. (2017). Output-based measurement of accounting comparability: A survey of empirical proxies. Journal of Accounting Literature, 39, 1-22.

Hadi, A. S. (1992). Identifying multiple outliers in multivariate data. Journal of the Royal Statistical Society, 54(3), 761-771.

Hendriksen, E. S. (1967). Toward greater comparability through uniformity of accounting principles. New York Certified Public Accountant, 37(2), 105-115.

Hoechle, D. (2007). Robust standard errors for panel regressions with cross-sectional dependence. The Stata Journal, 7(3), 1-31.

Holthausen, R. W., \& Watts, R. L. (2001). The relevance of the value-relevance literature for financial accounting standard setting. Journal of Accounting and Economics, 31(1-3), 3-75. 
International Accounting Standards Board. (2018a). Conceptual framework for financial reporting.

International Accounting Standards Board. (2018b). Basis for conclusions on the conceptual framework for financial reporting.

Kim, R., Kim, S., \& Musa, P. M. (2018). When does comparability better enhance relevance? Policy implications from empirical evidence. Journal of Accounting and Public Policy, 37(5), 436457.

Kothari, S. P. (2001). Capital markets research in accounting. Journal of Accounting and Economics, 31(1-3), 105-231.

Lang, M. H., Maffett, M. G., \& Owens, E. (2010). Earnings comovement and accounting comparability: The effects of mandatory IFRS adoption [Working Paper]. Social Science Research Network. https://papers.ssrn.com/sol3/papers. cfm?abstract_id=1676937

Macedo, M. A., Machado, M. A. V., \& Machado, M. R. (2013). Análise da relevância da informação contábil no Brasil num contexto de convergência às normas internacionais de contabilidade. Revista Universo Contábil, 9(1), 65-85.

May, G. (1938). Uniformity in accounting. Harvard Business Review, XVII(1), 1-8.

Ohlson, J. A. (1995). Earnings, book values, and dividends in equity valuation. Contemporary Accounting Research, 11(2), 661-687.

Reina, D. R. M., Carvalho, L. N. G., Reina, D., \& Lemes, S. (2019). Comparabilidade dos relatórios financeiros e informatividade dos preços das ações no Brasil. Revista Contemporânea de Contabilidade, 16(39), 177-198.
Ribeiro, A. M., Carmo, C. H. S., Fávero, L. P. L., \& Carvalho, L. N. (2016a). Poder discricionário do gestor e comparabilidade dos relatórios financeiros: uma análise do processo de transição regulatória da contabilidade brasileira. Revista Contabilidade \& Finanças, 27(70), 12-28.

Ribeiro, A. M., Carmo, C. H. S., Fávero, L. P. L., \& Carvalho, L. N. G. (2016b). Comparabilidade x uniformidade dos relatórios financeiros: uma análise empírica durante o período de transição regulatória da contabilidade brasileira ao padrão internacional. Advances in Scientific and Applied Accounting, 9(3), 262-282.

Santos, S. M., Lemes, S., \& Barboza, F. L. M. (2019). O value relevance é relevante? Revista de Contabilidade e Organizações, 13, Artigo e152518.

Schipper, K. (2003). Principles-based accounting standards. Accounting Horizons, 17(1), 61-72.

Schipper, K., \& Vincent, L. (2003). Earnings quality. Accounting Horizons, 17, 97-110.

Scott, W. R. (2015). Financial accounting theory (7a. ed.). Pearson Canada Inc.

Simmons, J. K. (1967). A concept of comparability in financial reporting. The Accounting Review, 42(4), 680-692.

Trueblood, R. M. (1966). Accounting principles: The board and its problems. Journal of Accounting Research, 4, 183-191.

Yip, R. W. Y., \& Young, D. (2012). Does mandatory IFRS adoption improve information comparability? The Accounting Review, 87(5), 1767-1789.

Zeff, S. A. (2007). Some obstacles to global financial reporting comparability and convergence at a high level of quality. The British Accounting Review, 39(4), 290-302. 